${ }^{1}$ Dr. Marium Begum Associate professor Dept. of pediatrics Bashundara Ad-din Medical College

${ }^{2}$ Dr. Dipa Saha

Assistant professor

Dept. of pediatrics

National Institute of Neurosciences (NINS), Dhaka

${ }^{3}$ Dr. Mahmuda Hasan

Professor

Dept. of pediatrics

Ad-din Medical College

${ }^{4}$ Dr. Wahida Hasin

Assistant professor

Dept. of community medicine

Bashundara Ad-din Medical College

${ }^{5}$ Dr. Nadira Sultana

Assistant professor

Dept. of gynae \& obs

Bashundara Ad-din Medical

College \& Hospital

${ }^{6}$ Dr. Chinmoy Kumar Saha

Assistant professor

Dept. of Medicine

Comilla Medical College

\section{Correspondence}

Dr. Marium Begum

Associate professor

Dept. of pediatrics

Bashundara Ad-din Medical College

e-mail : mariumb71@yahoo.com

\title{
Outcome of microbiologically proven pneumonia by nasopharyngeal aspirate of infant attending in a tertiary care hospital
}

\author{
M Begum ${ }^{1}$, D Saha ${ }^{2}$, M Hasan ${ }^{3}$, W Hasin ${ }^{4}$, N Sultana ${ }^{5}$, C K Saha ${ }^{6}$
}

\section{Abstract}

Background : In Bangladesh, recent estimates suggests that $22 \%$ of under-five death and $13.1 \%$ of neonatal death is due to pneumonia. Its etiology usually remains unknown and problems is increasing with drug resistant infections.

Objective : The aim of this study is to evaluate the outcome of microbiologically proved pneumonia of the infant by nasopharyngeal aspirate culture.

Methods : This prospective study was conducted at the Department of Pediatrics and Neonatology, Addin Medical college hospital, Dhaka from January to July 2015. A total of 30 hospitalized infants of either sex with pneumonia fulfilling the WHO criteria and radiologically confirmed were enrolled in the study. Child with congenital heart disease or chronic respiratory disease, who did not give consent were excluded from the study. The study cases were divided into three groups on their final outcome as improved, not improved (prolonged hospital stay) and expired.

Results : Among 30 study cases mean age was $39.7 \pm 45$ days, most of them were male $19(63 \%)$; case fatality rate was $10 \%$. Organisms were isolated from $47.3 \%$ cases of nasopharyngeal aspirate culture, among them Gram-ve bacteria were $10(34 \%)$, gram + ve $3(10 \%)$ and fungal $1(3.3 \%)$. Mixed bacterial growth were $4(13 \%)$ and no growth were $12(40 \%)$ cases. Acinetobacter was found in $8(26.7 \%)$, Coagulase negative staphylococcus $2(6.7 \%)$. Additionally, MRSA, pseudomonas and E.coli species were identified in $1(3.3 \%), 1(3.3 \%)$, and $1(3.3 \%)$ of the cases respectively. All infant who had gram + ve $3(100 \%)$ and fungal $1(100 \%)$ growth on their nasopharyngeal culture were improved. On the other hand, among the gram -ve cases mortality rate was high $2(20 \%)$ and also required prolonged hospital stay 2(20\%). Among the cases who had mixed organism 2(50\%) of them were improved and 2(50\%) required prolonged hospital stay. Majority of the cases were improved $10(83 \%)$ those who had no growth on their NPA culture followed by $1(8.3 \%)$ had prolonged hospitalization and $1(8.3 \%)$ was died.

Conclusion : Infant with severe pneumonia having younger age were at greater risk of mortality. Gram - ve organism in nasopharyngeal aspirate culture indicated poorer outcome and required prolonged hospital stay.

Key Words : Pneumonia, Nasopharyngeal aspirate culture

DOI: http://dx.doi.org/10.3329/nimcj.v9i1.35926

Northern International Medical College Journal Vol. 9 No. 1 July 2017, Page 267-270

\section{Introduction}

Globally Pneumonia remains the leading infectious cause of death among children underfive, killing 2,500 children a day. Pneumonia accounts for $15 \%$ of all under-five deaths and killed 920,000 children in 2015. Most of its victims were less than 2 years of old. ${ }^{1}$ In Bangladesh, recent estimates suggests that 22\% of under-fived death and $13.1 \%$ of neonatal death is due to pneumonia. ${ }^{2}$ Hospital based studies have reported that $20-30 \%$ of admission in under-five children are due to pneumonia. Case fatality rates in hospitalized children are reported to be between $8.7-47 \% .^{3}$
The ARI control program includes identification of children with pneumonia by clinical features and administration of antimicrobials with a presumption that majority of pneumonia in developing countries are because of bacterial pathogens. Respiratory infections cause a variety of clinical syndromes, of which pneumonia perhaps the most severe of all and is the most commonly associated with an adverse outcome, causing over $90 \%$ of all deaths. ${ }^{4}$ Pneumonia is frequently caused by varieties of viruses, bacteria, fungus or mycobacterium tuberculosis however, their isolation and identification in resource poor settings is expensive. Moreover, the etiology varies by age groups, nutritional 
status, geographical locations and settings in which they occur. ${ }^{5}$ Although its etiology usually remains unknown and problem increasing with drug resistant infections. ${ }^{6}$ However, precise diagnosis is difficult to make on the basis of clinical or radiological findings. ${ }^{78}$ In most reported studies, the organisms were isolated from blood, sputum, throat swab ${ }^{5}$ which either did not reflect the actual incidence or isolation of the causative organism. The organism can be isolated from specimens of empyema fluid, or lung aspirate, but this is rarely done. Culture based diagnosis is complicated by the technical difficulty of obtaining specimens. The diagnostic value of a positive blood culture is high, but its sensitivity is low $(1 \%-3 \%)$ for hospitalized children with bacterial pneumonia. ${ }^{8}$

There is a need to evaluate the outcome including-required change of antibiotics, prolonged hospital stay etc.

We therefore, conducted a study to evaluate the outcome of microbiologically proven pneumonia by nasopharyngeal aspirate of infant.

\section{Methods}

This prospective study was conducted at the Departments of Pediatrics and Neonatology, Ad-din Medical college hospital, Dhaka from January to July 2015. A total of 30 infant of either sex admitted with pneumonia fulfilling the WHO criteria of pneumonia ${ }^{9}$ and also radiologically confirmed pneumonia were enrolled in this study.

The case definition of pneumonia included children presenting with cough with difficult breathing, having increased respiratory rate (children $<2$ months; $>60 /$ minute, 2-12 months, $>50$ per minute) with chest indrawing. Children with co-morbidities like congenital heart disease or chronic respiratory disease, whose parents did not give consent, were excluded.

A pre-designed questionnaire was used for recording of demographic profile, clinical presentation, laboratory investigations, out come on treatment (according to hospital protocol). Relevant past and family history was enquired and recorded. Chest radiographs were done in all the patients before enrollment.

\begin{tabular}{|c|c|c|c|c|}
\hline $\begin{array}{l}\text { Variable } \\
\text { Demographic characteristics }\end{array}$ & $\begin{array}{l}\text { Improved(22) } \\
\text { SD }\end{array}$ & $\begin{array}{c}\text { Prolonged hospital stay(5) } \\
\text { SD }\end{array}$ & $\begin{array}{l}\text { Expired(3) } \\
\text { SD }\end{array}$ & p value \\
\hline $\begin{array}{l}\text { Age (mean } \pm \text { SD) } 39.7 \pm 45 \mathrm{~d} \\
\text { Sex } \\
\quad \text { Male } 19(63 \%) \\
\quad \text { Female } 11(37 \%)\end{array}$ & $\begin{array}{c}44.67 \pm 39.25 \\
13(43 \%) \\
9(30 \%)\end{array}$ & $\begin{array}{c}35.22 \pm 33.67 \\
3(10 \%) \\
2(7 \%)\end{array}$ & $\begin{array}{c}27.22 \pm 36.4 \\
3(10 \%) \\
0\end{array}$ & $\begin{array}{l}0.053 \\
0.07\end{array}$ \\
\hline Clinical characteristics & $\mathrm{N}(\%)$ & $\mathrm{N}(\%)$ & N (\%) & \\
\hline $\begin{array}{l}\text { Fever } \\
\text { Cough } \\
\text { Respiratory distress } \\
\text { Apnoea } \\
\text { Fast breathing } \\
\text { Poor air entry } \\
\text { CNS manifestation } \\
\text { Bleeding Manifestation }\end{array}$ & $\begin{array}{c}12(40 \%) \\
22(73.3 \%) \\
22(73.3 \%) \\
9(30 \%) \\
22(73.3 \%) \\
12(40 \%) \\
4(13.3 \%) \\
3(10 \%)\end{array}$ & $\begin{array}{c}3(10 \%) \\
5(16.6 \%) \\
5(16.6 \%) \\
2(6.6 \%) \\
5(16.6 \%) \\
2(6.6 \%) \\
1(3.3 \%) \\
0(0 \%)\end{array}$ & $\begin{array}{l}1(3.3 \%) \\
3(10 \%) \\
3(10 \%) \\
2(6.6 \%) \\
3(10 \%) \\
3(10 \%) \\
2(6.6 \%) \\
1(3.3 \%)\end{array}$ & $\begin{array}{c}0.364 \\
0.088 \\
0.30 \\
0.025 \\
0.621 \\
0.091 \\
0.033 \\
0.65\end{array}$ \\
\hline
\end{tabular}

Nasopharyngeal aspirates (NPA) were collected from all patients within 48 hours of the diagnosis of pneumonia using commercially available sterile disposable mucus extractor. Controlled suction catheter was connected with the sterile mucus extractor and passed through nostril. The sample was sent for culture sensitivity.

In the study the outcome was defined as- Improved (full recovery), Not Improved (prolonged stay in the hospital i,e hospitalization exceeding 7 full days) and Expired-(died). The antibiotics were changed according to NPA culture sensitivity. Discharge was considered when the child's respiratory rate reduced below the age-specific cut-off, with absence of chest in drawing, hypoxemia and no fever for at least 24 hours.

Data were analyzed by SPSS version 20. Results on continuous measurements are presented on Mean $\pm \mathrm{SD}$ and categorical measurements are presented in number (\%). Chi-squre has been used to find the significance on categorical scale between two variables.

\section{Results}

Among 30 study cases mean age was $39.7 \pm 45$ days. Majority of them were male 19(63\%). Study cases were classified into three groups those who improved/full recovery $(n=22)$, prolonged stay in hospital $(n=5)$ and those who expired $(n=3)$, during the course of treatment for pneumonia.

Infant who prolonged hospital stay and expired of pneumonia during hospitalization were younger age $35.22 \pm 33.67$ days and $27.22 \pm 36.4$ days respectively compared to full recovery group (age- $44.67 \pm 39.25$ days) p 0.053 . However, there was no significant difference in sex distribution $(p=0.07)$. On the other hand, there were no significant differences found among all the cases in their clinical presentation (fever, cough, respiratory distress, poor air entry) during admission. But apnoea was frequently seen among expired group compared to those who improved $p=0.025$. There was significant difference among the groups in the frequency distribution of central nervous system (CNS) manifestation (p 0.033) showed in (table I). 
Majority of the study cases who were improved had right upper lobe consolidation $10(45 \%)$ followed by bilateral patchy opacity $6(27.27 \%)$, left sided patchy opacity $3(13.63 \%)$, left upper lobe consolidation $2(9.09 \%)$ and $1(4.54 \%)$ had bilateral patchy opacity with pneumothorax. Among the cases who required prolonged hospitalization, most of them had left sided upper lobe consolidation 2(40\%) and bilateral patchy opacity 2(40\%). All of the infant who were died, their radiological features were bilateral patchy opacity. Children who died/ prolonged hospital stay, compared to those who improved had significantly abnormal radiological findings shown in (table II) $p=0.011$.

\begin{tabular}{|c|c|c|c|c|}
\hline $\begin{array}{l}\text { Variable } \\
\mathrm{X} \text { ray chest }\end{array}$ & $\begin{array}{c}\text { Improved (22) } \\
\mathrm{N}(\%)\end{array}$ & $\begin{array}{c}\text { Prolonged hospital stay (5) } \\
\text { N (\%) }\end{array}$ & $\begin{array}{l}\text { Expired (3) } \\
\mathrm{N}(\%)\end{array}$ & p value \\
\hline \multicolumn{5}{|l|}{ Consolidation } \\
\hline Rt upper lobe & $10(45.45 \%)$ & $1(20 \%)$ & 0 & 0.011 \\
\hline Lt upper lobe & $2(9.09 \%)$ & $2(40 \%)$ & 0 & \\
\hline \multicolumn{5}{|c|}{ Patchy opacity } \\
\hline Bilateral & $6(27.27 \%)$ & $2(40 \%)$ & $3(13.63 \%)$ & \\
\hline Left sided & $1(4.54 \%)$ & 0 & 0 & \\
\hline $\begin{array}{l}\text { Bilateral patchy } \\
\text { opacity with } \\
\text { pneumothorax }\end{array}$ & $1(4.54 \%)$ & 0 & 0 & \\
\hline
\end{tabular}

Gram-ve bacteria were isolated in $10(34 \%)$ cases followed by gram+ve $3(10 \%)$ \& fungal $1(4 \%)$, mixed bacterial growth were present in $4(13 \%)$ cases and no growth were found in $12(40 \%)$ cases from nasopharyngeal aspirate (Figure1).

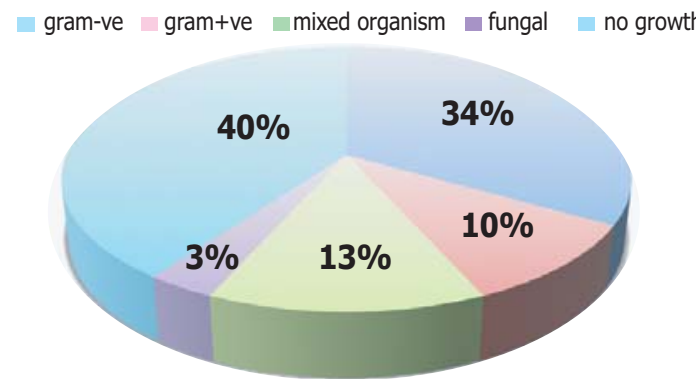

Figure 1: Microbiological profile of nasopharyngeal aspirate culture

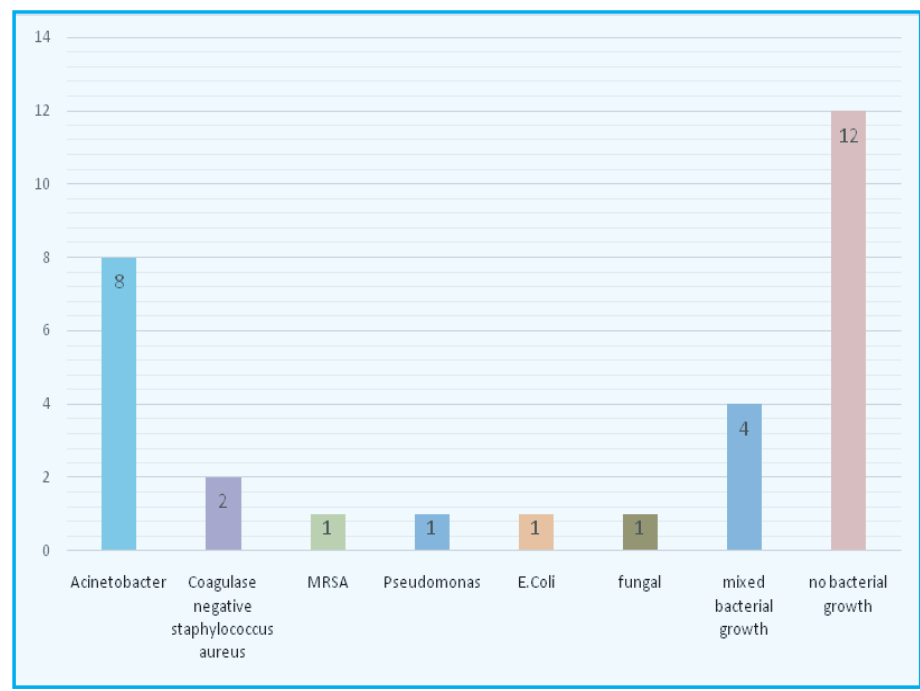

Figure 2: Microbiological pattern among the study cases $\mathrm{N}=\mathbf{3 0}$
Acinetobacter was found in $8(26.7 \%)$, Coagulase negative staphylococcus $2(6.7 \%)$. Additionally, MRSA, pseudomonas and E.coli species were identified in $1(3.3 \%), 1(3.3 \%)$, and 1 $(3.3 \%)$ of the cases respectively (Figure 2 )

All infant with pneumonia who had gram +ve (100\%) and fungal $1(100 \%)$ growth on their nasopharyngeal culture were improved. On the other hand who had gram-ve bacterial growth, their mortality were high $2(20 \%)$ and also required prolonged hospital stay $2(20 \%)$. Among the gram-ve cases $6(60 \%)$ were improved. 2(50\%) were improved and 2(50\%) had prolonged hospitalization among the cases who had mixed bacterial growth in nasopharyngeal aspirate. Most of the cases $10(83 \%)$ were improved followed by $1(8.3 \%)$ were died and $1(8.3 \%)$ had prolonged hospital stay, who had no growth on their nasopharyngeal culture. Moreover this study found that infant who didn't improved/ expired had Gram negative bacteria on nasopharyngeal aspirate culture and most of the cases with gram +ve bacterial growth and no growth were improved which found statistically significant shown in table III $(p<0.031)$

\section{Table III : Comparisons of NPA culture between infants of 3 groups} with pneumonia $(\mathrm{N}=30)$

$\begin{array}{lccc}\text { Variable } & \text { Improved (22) } & \text { Prolonged hospital stay (5) } & \text { Expired (3) } \\ \text { Nasopharyngeal aspirate culture } & \mathbf{N}(\%) & \text { N (\%) } & \text { N (\%) } \\ \text { Gram +ve bacteria (3) } & 3(100 \%) & 0(0 \%) & 0(0 \%) \\ \text { Gram -ve bacteria (10) } & 6(60 \%) & 2(20 \%) & 2(20 \%) \\ \text { Fungus (1) } & 1(100 \%) & 0(0 \%) & 0(0 \%) \\ \text { Multiple bacterial growth (4) } & 2(50 \%) & 2(50 \%) & 0(0 \%) \\ \text { No bacterial growth (12) } & 10(83.3 \%) & 1(8.3 \%) & 1(8.3 \%) \\ \text { p value: } 0.031 & & & \end{array}$

\section{Discussion}

We conducted this study to identify the Outcome of microbiologically proven pneumonia by nasopharyngeal aspirate of infant attending in a tertiary care hospital, the case fatality rate of pneumonia among hospitalized infant was $10 \%$ in this study which compares with the reported case fatality rate of $10.5 \%{ }^{10}$ and $10.45 \%{ }^{3}$ in similar settings.

Neonates were at a higher risk of death than were older infant. Mortality associated with severity and young age is consistent with other studies ${ }^{11}$. Similar to other studies, the co-morbid condition apnea, CNS manifestation were significantly frequent among those who died compared to those who survived ${ }^{5,11}$. Demers et al reported that altered sensorium in children with acute respiratory tract infection are associated with increased risk of mortality by 3.2 times. ${ }^{12}$

In the present study, we identified etiological agent by the conventional culture studies of NPA in $47.3 \%$ cases, predominance of gram negatives in this population (figure1). Taneja, et al $^{13}$ and Shahunja et al ${ }^{14}$ also found gram-ve 
organism predominantly among their study population. Results of the previously published Indian study showed that H.influenzae was the commonest isolate whereas studies in Brazilian children have documented gram negative enteric bacilli as the commonest cause. ${ }^{15,16,17}$ Our isolated bacterial agents significantly differ from the common bacterial etiology of pneumonia in this age group of children ${ }^{18,19}$. Poor hygiene and low immunity among infancy, a common co-morbidity of pneumonia in developing countries may be a factor that explains our observation. Isolation of bacterial agent in nearly all children indicates an association of bacterial pathogens in pneumonia. However, the isolation of multiple bacterial agents from individual NPA makes it difficult to define a causal relationship.

The other factor associated with the morbidity of pneumonia in infant in our study was an abnormal chest radiograph. These included those showing bilateral patchy infiltration. An abnormal chest radiograph was more likely to be due to bacterial infection and need either a change of antibiotics or a prolonged stay in the hospital. Karalanglin et al in their study also demonstrated that abnormal radiological findings were independent factor for morbidity of pneumonia and determining the poor outcome. ${ }^{10}$ Abnormal chest radiograph were associated with the risk for need of change of antibiotics.

The children who survived required a longer time to recover from illness if they were younger or had gram negative bacterial pneumonia.

\section{Conclusion}

Infant with severe pneumonia having younger age, apnea and CNS manifestation were at greater risk of mortality. Patient with abnormal chest radiograph and gram-ve organism in nasopharyngeal aspirate culture had poorer outcome and required prolonged hospital stay among the infant with pneumonia.

\section{References}

1. http://www.data.unicef.org/childhealth/pneumonia.html Despite steady progress, pneumonia remains one of the single largest killers of young children worldwide (June 2016)

2. Bangladesh Demographic Health Survey. 2011

3. Sehgal V, Sethi GR, Sachdev HP, Satyanarayana L: Predictors of mortality in subjects hospitalized with acute lower respiratory tract infections. Indian Pediatr1997, 34:213-219.
4. Black RE, Cousens S, Johnson HL, Lawn JE, Rudan I, Bassani DG, et al. Global, regional, and national causes of child mortality in 2008: a systematic analysis. Lancet 2010;375:1969-87.

5. Chisti MJ, Tebruegge M, La Vincente S, Graham SM, Duke T (2009) Pneumonia in severely malnourished children in developing countries mortality risk, aetiology and validity of WHO clinical signs: a systematic review. Trop Med Int Health 14: 1173-1189.

6. Lister PD. Multiply-resistant pneumococcus: therapeutic problems in the management of serious infections. Eur J ClinMicrobiol Infect Dis 1995; 451:S18-25.

7. Swingler GH. Radiologic differentiation between bacterial and viral lower respiratory infection in children: a systematic literature review. ClinPediatr2000; 39:627-33.

8. Ruuskanen 0 , Mertsola J. Childhood community-acquired pneumonia. SeminRespir Infect 1999; 14:163-72.

9. WHO (2013) Pocket book for hospital care of children: guidelines for the management of common childhood illness 2nd ed. Geneva: World Health Organization.

10. KaralanglinTiewsoh, Rakesh Lodha, Ravindra M Pandey, ShobhaBroor, M Kalaivani and Sushil K Kabra. Factors determining the outcome of children hospitalized with severe pneumonia. BMC Pediatrics 2009, 9:15.

11. Karimeldin Mohamed Ali Salih1, Jalal AliBilal, Amani Hussein Karsani.Risk Factors of Mortality among Children Admitted with Severe Pneumonia at a Reference Hospital in Khartoum, Sudan. American Journal of Medicine and Medical Sciences 2015, 5(3): 130-134

12. Demers AM, Morency $P$, Mberyo-Yaah $F$, Jaffar $S$, Blais $C$, Somsé $P$, Bobossi $G$, Pépin J: Risk factors for mortality among childrenhospitalized because of acute respiratory infections in Bangui,Central African Republic. Pediatr Infect Dis J 2000, 19:424-432.

13. Taneja J, Abida M, Ashraf M, MeherR ,Mithlesh A. Acute Lower Respiratory Tract Infections in Children.Indian Pediatrics 2009;46:509-511.

14. KM shahunja, MA salam, $T$ Ahmed et al.Bacterial Isolates from Tracheal Aspirates and theirAnti-microbial Susceptibility in Mechanically-Ventilated Children with Pneumonia Admitted to an Urban Critical Care Ward.

15. Patwari AK, Bisht S, Srinivasan A, Deb M, Chattopadhya D. Aetiology of pneumonia in hospitalized children. J Trop Pediatr 1996; 42: 15-20.

16. Wolf B, Gama A, Rey L, Fonseca W, Roord J, Fleer A, et al. Striking differences in the nasopharyngeal flora of healthy Angolan, Brazilian and Dutch children less than 5 years old. Ann Trop Paediatr 1999; 19: 287-292.

17. Wolf B, Rey LC, Moreira LB, Milatovic D, Fleer A, Verhoef J, et al. Carriage of gram-negative bacilli in young Brazilian children with community-acquired pneumonia. Int J Infect Dis 2001; 5: 155-159.

18. McIntosh K (2002) Community-acquired pneumonia in children. N Engl J Med 346: 429-437.

19. Morar P, Singh V, Makura Z, Jones AS, Baines PB, et al. (2002) Oropharyngeal carriage and lower airway colonisation/infection in 45 tracheotomised children. Thorax 57: 1015-1020. 